\title{
Which One of Standardization or Customization Works the Best When It Comes to Online Marketing?
}

\author{
Ashraf Hossain, Rashad Yazdanifard \\ Help College of Arts and Technology, Centre for Southern New Hampshire University, Kuala Lumpur, Malaysia \\ Email: ashrafmohd654@gmail.com, rashadyazdanifard@yahoo.com
}

Received 6 November 2014; accepted 7 February 2015; published 10 February 2015

Copyright @ 2015 by authors and Scientific Research Publishing Inc.

This work is licensed under the Creative Commons Attribution International License (CC BY). http://creativecommons.org/licenses/by/4.0/ (c) (i) Open Access

\begin{abstract}
Online marketing has influenced the consumers all around the world. This opens up a way for the small enterprises to enter the international market and enjoy the benefits like the MNCs located in different parts of the world. Advertising products and manipulating the customers to buy is one of the techniques used by the international companies. As a result some companies take standardization as an incentive to attract customers while some use customization or personalization to manipulate them. This as a result that has created a debate between different marketers to choose a beneficial way to satisfy by attracting different customers. This article focuses on various problems which marketers face in terms of online retailing as well as different obstacles encountered by consumers while making buying decisions for standardized or customized products through online Medium (Internet).
\end{abstract}

\section{Keywords}

Online Marketing, Standardization, Customization, Consumers, Products, Advertisements

\section{Introduction}

Companies in today's world are mostly based on the customer satisfaction concerning profitability. The major problem for these companies who are marketing their product abroad is to answer the question "which one, standardization or customization is important for a good outcome?” This mostly happens when a company takes an international approach to cover a large area and satisfy their need. Standardization and customization are the two components which act as an incentive for the organization to achieve the organizational goals; this also acts as part of marketing philosophy such as customer satisfaction. In this world of $21^{\text {st }}$ century, people are becoming 
more preferential and cautioned about the products being produced. Standardization and customization created controversies among the MNCs asking which among them would be beneficial to its customers and the organization.

Core competencies are needed to be created by the companies in order to be stable. Different concepts should be taken care of while expending abroad like gender, cast, religion, uncertainties faced by countries. According to Larson 1998 the similar issues of e-marketing strategies are the failure in classifying the characteristics of each product, non-suitable choice of channels, pricing and promotion in the earlier research (Larson 1998 as cited in Kiang and Chi, 2001) [1]. There were also cases which were being reported as a failure. Promotion strategies with time have become more advanced with internet.

Online selling has becoming one of the popular and effective ways of marketing. Being depended on internet created a sensational topic among marketers. MNCs having their business abroad have influenced a lot of people by communicating and walking with the latest trend. This also encouraged the SMEs to expend their business abroad and take advantage of the international marketing. SMEs with their IT innovations in recent years started successfully competing with huge companies (Dobra, 2011) [2]. Small and large enterprises also are influenced by the different standardization and customization strategies. Standardization increased demand for different products as they tend to be compatible, comparative, recyclable and most importantly sustainable. Customization on the other hand turned to be more successful with their different approach towards customer satisfaction. Web designing promoted by different web companies made customization more compact for the customer to demand their need by designing their own product. Besides, the benefits which are provide by both the strategies there are some cons which are faced both marketers like, freight, transportation, pricing, delay in meeting the demand, not meeting the consumer preferences perfectly, and durability of the product. Both this incentives created confusion between the MNCs and SMEs, as both strategies tends to be successful over time.

\section{Online Marketing}

The multinational companies (MNCs) today uses web to reach their customers who are present globally (Ellsion 2000, Riedman 2000, and Taylor 2005 as cited in Yuhmin, C. 2009) [3]. E-commerce or online marketing has become one of the business initiatives over time. Modern MNCs use online as a marketing means. Overtime bricks and mortars have formed many online stores which were found to be profitable by their increase in number of sales (Dinner, Heerde, Neslin, 2014) [4]. This huge sale of products indicates a shift in the behavior of the consumers from offline marketing which is visiting different places to buy. According to a report by Boston Consulting Group (2014) the internet economy will grow up to $\$ 4.2$ trillion by 2016 in G-20 economies (Ashraf, Thongpapanl, and Auh, 2014) [5] which in turn helped the economy to grow. According to Jarvenpaa, Tractinsky, Saarinen, 1999, a cross cultural research has shown the element which makes e retailer trustworthy is by meeting the expectations of different customers from different cultures (Ashraf, Thongpapanl, and Auh, 2014) [5]. Consumers are given the option to comment on the websites about the products one bought and about the customized or standardized approach towards the marketing.

Advertisement is what the online marketing is based on. To make the advertisement effective to customers, advertisers or advertising networks hire a third party to syndicate advertisements (Edelman, 2014) [6]. Advertisements presented to customers should be trustworthy. Paying during an online marketing is one of the important factors which are to be considered by the consumers. Advertisement on the other hand is turning to be an expensive approach for the marketers in order to promote their product. Consumers in this communication ground are aware of, shows their behavior, and most importantly involves in purchasing a product (Yuhmiin, C. 2009) [7]. According to Mackenzie and Lutz, behavior towards the advertisements has a great impact towards the attitude of an advertisement and the brand (Mackenzie, and Lutz 1989 as cited in Moller, J., Eisend, M., 2010) [8]. An approach known as affiliate marketing, pay per sale or cost per acquisition was made in order to reduce the threat of being cheated by the tempted advertisers were introduced which focused on pay while purchase (Edelman, 2014) [9]. Online marketing has made the purchasing more easy and flexible. Consumers Besides the benefit that online marketing provides us, online shoppers in e-commerce faces numerous problems like security of card information, product quality, delivery delays and other issues (Knezevic, Jakovic, Strugar, 2014) [10]. Online marketer in this case should build trust in internet merchant, in internet as a shopping channel and as a business and regulatory environments (Knezevic, Jakovic, Strugar, 2014) [10]. According to Pattek smart marketers first will litter potential buyer's tracks using actionable data to help them solve their problems. 
When the potential buyers are most open to accept marketing messages, only then ways to contact them should be devised (Pattek as cited in Vanzile, J., Hosford, C., 2013) [11].

\section{Standardization in Online Marketing}

Marketing academia is divided as the marketing mix which has 4 Ps of marketing (Constantinides, E. E., 2006) [12]. Product among the 4 Ps of marketing (product, promotion, price and place) is a critical decision for an online marketer to make. Products which is to be provided to the customers at the end should satisfy the customer and meet their requirements, so the marketer in this case take decisions in order to create a standardized product which would last for long and be compatible to carry and use. The electronic marketer keeps standardization overtime as an important notification. According to Capon and Hulbert 2000, Lewis and Bridger 2000, researchers has shown that today's consumer has their own demand, prefer individualist rather than collectivist, rather rely on themselves than on others, and well informed with the help of the technology (Capon and Hulbert 2000, Lewis and Bridger 2000 cited in Constantinides, E. E., 2006) [12].

According to Czinkota and Ronkainen (2004) Companies over time had found 4 alternatives when deciding the product to be sold globally. Those are

a) Offering the same product all around.

b) Modifying the same product for diverse markets.

c) Producing new products for international markets.

d) Creating a good product by combining all differences from the market, to sell it globally. (Czinkota, Ronkainen, 2004 as cited in Loukakou, Membe, 2012) [13].

The objective of a successful marketer is selling the product and making it reach in the hands of the customers. Advertisement is another paradigm of promotion strategy. Advertisement online does not value the standardization so the online marketers tend to provide details about the products which informs the consumers about the final product that the consumer is going to purchase to satisfy the consumers need. Many consumers' faces trust issues regarding the advertisements which are used for promotion. Several different tools besides advertisements are used to promote a product. Selling being one of the main objectives of marketing is necessary to be taken care of. Sales promotion in the other hand act better for small businesses as it is cheap and effective way to attract customers. Different companies even try to differentiate their product from its competitors by standardizing and using the online promotional tool.

Apart from the different challenges faced by the online marketer, cultural differences play an important role. Standardization in some countries as marketing strategy did not tend to be successful as the culture followed in different countries differs from one another. A company must or should take care of the cultural aspects while it is global (Meyer, Bernier, 2010) [14]. So a marketing strategy should be implemented in order to find the solution for the problems and manufacturing the product according to each country specifications. Online shoppers on the other hand face issues related to trust, as some of the content depicted about the product online does not match the original product. Another complain that are faced by the marketer is regarding the standard life of the product which is being sold. The sold standardized product as promised tends to diminish its durability over time. Not all products in this case are non-durable. Marketers in solving this problem in progress provided catalogues providing standardized information about the product. According to Doole and Lowe, (2001), these problems while standardizing a product can be overcome by using the Hofstedes five cultural dimensions which include which includes language, religion, values and behaviors, education, social organization, technology and material culture, aesthetics, and finally laws and politics (Doole and Lowe, 2001 as cited in Meyer, Bernier, 2010) [14]. Some companies use their market intelligence producing a distinct standardized product which can be adopted by all parties without barriers.

\section{Customization in Online Marketing}

Consumers nowadays are much more aware and are updated with the latest trend. Walking with the latest trend made the present consumers more formal and changed their perspective towards the product which is provided to them. Providing service to the consumers according to their need and at their doorstep is the best alternative that customization puts forward. Retailers utilize Big Data to present a customized set of items to their clients it has been a main thrust behind Amazon's prosperity. Presently brands are making personalization an enormous stride forward into mass customization. According to a research on the decision-making by the customers, con- 
sumer preferences are probably influenced by the choices they are presented with (Yoon and Simonson 2008, as cited in Voeth, M., Herbst, U., and Liess, F. 2013) [15]. Personal websites are established to help customers to fulfill their requirements through customization. For e.g. Trek empowers cyclists to manufacture a bicycle starting from the earliest stage. Furthermore, Brooks Brother permits man to make their own particular suits (Spaulding and Perry, 2013) [16].

Online shoppers are found to be more attached to the companies they shop from. The companies, which are global, tend to be more effective in their work by the providing the customer with the option to demand their own need and to satisfy them according to their preferences. In some cases, customers might not be specific about how the product should look like, and then it turns to the marketers to identify what the customer wants by running researches and knowing about the consumer behavior. Social networking sites are also used as a tool for marketing customized products. The main objective of customization is to represent once brand. Designers ruling this website make the exact copy of the product being configured by the customers. Advertisers over decades acted a means by shortening the path between the consumers and retailers. Different ads are provided by different websites for e.g. An online store which sells laptop or mobiles phones provide the web designing option in which customer designs the product according to his/her preferences. With a special agreement, the consumer packaged goods companies will usually fund the customized promotion (Zhang and Wedel, 2009) [17]. These promotion techniques are sometimes irritating but attract customers to visit their website and post their demands. The analysts found that individuals who saw the customized item data were large less inclined to purchase an item on the day they were demonstrated the notice than the individuals who were demonstrated the more nonexclusive variant. This informed the online retailer to be more specific about the product they are planning to sell.

A number of industries moved from their goal of producing in high quantity to serving a large number of customers through customization. The most important issues faced by the online sellers are meeting the requirement of the customers within the given time and as specified. Sometimes companies will cover the expenses for the transportation of the product however, customers have to repay it at the time of arrival. Issues with online shopping can be particularly hard to solve if the vender is found in different nation. Another problem relating to customization is it leaves its brand everywhere. The cost incurred is much more higher compared to a standardized product. Large numbers of choices are provided to the customers. There are many other issues, which are faced by the online marketers like confidentiality of information, pricing disadvantages, strong competition, and difficulty in completing transaction. Thus, a suitable structure should be created to verify the costs and monetary outcome of the online marketing, to be sure that there are more of positive than of negative aspects about the organization. (Adam, C. 2011) [18]. Another measure which is used widely by the marketers is grouping customer preferences together in a range so that they can be fulfilled at once. A survey on customer preferences should be done to create the website based on the preferences.

\section{Standardization Differs Customization in Online Marketing}

Talking about services or international services some of the services were provided internationally before the invention of the word scientific management or before the inventions of the marketing course (Lovelock, 1999) [19]. In marketing organizations look for building relationships with different customers which was later replaced by customization. Analysis on the perception of the consumers towards customization helps the producer to produce the right product for the right customer within the capabilities of the producer (Xuehong, D., Jianxin, J., and Tseng, M. M., 2006) [20]. MNCs should take care of the cultural aspects while making a standardized or a customized product. They also should consider other limitations while manufacturing different products. Two major developments increased the conflict between standardization ad customization. Firstly, being dependent on the technology reduced the cost of production and communication. Secondly, consumers are becoming more heterogeneous towards product purchase (Franke, N., Keinz, P. and Steger, C.J., 2010) [21]. However, most of the following study and investigation in this research paper on this following topic is accumulated in all of the four strategic areas that is made up of the marketing mix which are product, price, promotion and place (Dimitrova, B., and Rosenbloom, B., 2010) [22]. Both this strategies in marketing are ineffective if the four Ps of marketing mix are not balanced. Globalization around the world has influenced the consumers by creating awareness through choices. The different preferences by consumers had a great impact on the marketer to decide which strategy to follow. As we know, global resources is essential for the survival of human kind and apart 
from providing the basic needs of a person, it also offers us with abundance of understanding in the sense of upcoming markets and technology appliances, however in global resources of the MNEs appears to be underused (Peters, Lois S. 2010) [23].

Consumers today are more dependent on internet which reduced the distance of the international marketers and opened a path for them to be familiar with the preferences that different consumers have. To know which best alternative to choose in marketing an assessment on these two different marketing strategies should be run. A research has shown that, a need for effective determination is necessary as marketing functions are concerned (Tim Amblers and John H Roberts 2008, Rust, Lemon and Zeithmal 2004; Srivastav et. al 2006; David W. Stewart 2009 as cited in Mishra, Misra, 2012) [24]. This research can be done by regulating the satisfactory levels of the different customers shopping online through web. This online shopping has turned the consumer preferences into an objective for the marketers. Researchers believe that content and reliability are the main factors to be considered while evaluating the performance of the different websites (Mishra, S. and Misra, M. 2012) [24]. Since the consumer preferences are becoming more homogeneous, standardization is necessary. Fashion products in this case were getting more advantage by the standardizing strategy but other fields like food and beverage were hard to standardize, so standardization was called certain. Customization on the other hand became popular among the marketers as it is considered to be a profitable approach taken by the marketers. And to the customization being not 'free' and it also needs to be traded-off against lead, time, cost, and other aspects, the empirical evidence has recommended were viewed more realistically (Mccutcheon et al., Squire et al. as cited in Wong, H., Eyers D., 2011) [25]. Thus while taking a decision about the customization level; the industries must consider the tradeoffs. This approach towards society through customization can be done through innovation.

Gradually over time, standardized products were more preferred by the marketer to produce and sell for consumers to be purchased. It turned to be one of the profitable approaches because of the less cost involvement. According to Mattson, Hannaford, Page and Siemplenski, it is claimed that firms can be more profitable by standardizing their system (Mattson 1973: 109; Hannaford 1976: Page and Siemplenski 1983: 91 as cited in Davies, Brady, Hobday 2007) [26]. This standardized product are sold through different promotion strategies like campaign e.g. Red bull focused primarily on Europeans and attracted a huge number of customers by sponsoring sport stuffs like bikes; skate boarding, flying sports etc. in contrary customization attracted their customers by their online promotion strategy, which is advertisement. These advertisements are used as a technique to manipulate consumers by asking their preferences to put up on internet. Five techniques of attaining customization globally for a standard product observed by Pine were:

1) Providing customized service for the standard product.

2) Products which are customizable are to be created.

3) Product delivery should be customized in order to save the standard related to the packaging of the product.

4) Responses and feedbacks are to be provided online.

5) Modules are to be created for the mechanism of this technique (Duray, 2002). [27]

Certain points should be given importance while considering the differences between standardization and customization:

a) Products which are in different value chain in market need more customized marketing strategy (Baalbaki and Malhotra 1995) [28].

b) Essential products should be standardized greatly.

c) Customization is necessary when there is a rise in the culture differences happening because of the online ads which use different symbols and idioms which are against ones culture to represent its product.

d) Price related factors may affect the products which are being standardized. Therefore a greater customized theme is necessary to regulate the price.

e) Fluctuations in the exchange rates might hinder the process of price standardization.

f) Since the prices determined by the online marketer are not negotiable a standard price should be determined which can be affordable.

g) A standardized marketing plan should be built in order to discover a distribution strategy while providing service.

h) The differences in consumer preferences that are located in different nations make the marketing strategies more complex to be followed by the distributers.

i) Since there are a lot of differences in the attitudes of the customers towards different products, customization is the preferable one for the marketers to follow. 
j) Building trust and keeping the securities private should be the main objective of the marketers in online marketing.

These points bring out the differences between the two marketing strategies and their outcomes concerning the different marketing mix. Marketers create different modules consecutively to overcome the issues relating to online marketing. Issues discuss previously can be solved by taking necessary measures against them.

\section{Discussion}

As observed by Dobra (2011), firms tend to be internationalizing as they realize that going global is beneficial as compared to domestic. This approach of being global turned to be successful over time due to the less cost involvement in manufacturing product. This article also covers the sensational topic of online marketing which plays a greater role in being cost effective and growing internationally. MNCs within time had reduced its cost of expending its business through online marketing. Online marketing among marketers has created a debate on the topic arguing, which of the two methods is more beneficial for firms to grow and influence its customers through their service. Different issues should be taken care of when standardizing or customizing a product like differences in culture, cast, religion for e.g. Pork as a non halal or prohibited item according to religion is banned selling in Saudi Arabia. Certain other issues of such types should be taken care of while going global and getting customized greatly. Different marketing strategies should be planned for both different approaches.

Standardization is the second topic discussed in this article. This phrase talks about the different ways to approach to customers through standardization. The 4Ps of marketing mix should be considered before standardizing a product this is discussed in the third part which talks about the customization benefits in online marketing as well. Standardization means modification in the product by having an approach of making the complex task easier for the consumers. This meaning turned to be a great and successful advantage for a marketer to standardize product and attain the objective of the firm through customer satisfaction. This article discussed about the promotion strategies followed by the marketer to sell a standardized product and get benefitted. The article also discussed about the different problems faced by the marketer in selling the product and gaining customer trust through advertisement as most ads today are faked to cheat consumers.

Customization on the other hand means satisfying consumer by fulfilling their needs as preferred and personally. Customization in online marketing is preferred to be more demanded by consumers as reported by different researches. It's because of the homogenous preferences that customer preserve among themselves. This article discusses why customization is the best alternative to be preferred. Web designing option opened a way for the consumer's to design one's own preference and demand. Advertisements in customization play an important role as a promotional technique to be used as. This article also discusses about how different problems related to mass customization can be solved. Building trust is the major problem faced by the marketers participating in customization. This article explains the solutions for this issue. Online shoppers in today's world are becoming more cautioned while shopping online. Certain measure like soft communication can create a strong bond between the customers and the seller which may build a trust around the firm.

The debate between the customization and standardization among marketers created a conflict. Marketers create modules to solve this conflict between both the strategies. As discussed in the third part of this article standardization and customization in online marketing is one of the beneficial ways to start a cost effective business. SMEs with this innovation were motivated to internationalize there business effectively and efficiently. This section of the article also talks about the different approaches that Pine believes should be taken to balance the marketing mix. This research paper also noted the important points which should be considered while approaching through customization and standardization.

\section{Conclusions}

MNEs in today's world are based on standardization then on customization while SMEs prefer to follow customization strategy for getting global. Promotion in marketing mix in this case plays a significant role to influence and attract different customers. There are several factors to be taken care of while promoting a product online, this promotion strategy chosen by the marketer should be beneficial for both the consumers and the seller. Standardization and customization has there won benefits which the marketer uses to manipulate customers. Customization is preferred more by the consumers than standardization when it comes to online marketing. Customization provides the customers to demand their own preferences by using the latest innovation of web designing. 
Standardization on the other hand gives number of choices to the people who are sustainable and not harmful for the consumers but limits the usage within the same products. One word which explains standardization is sustainable modification. However, customization over time has turned to be successful due to their persuasive influence over consumers.

Marketers take necessary decisions by creating a marketing mix module. This module considers the necessary steps to be taken while choosing a strategy. Standardization concerning this tends to be beneficial, as the cost involved for standardizing a product has reduced and the web based promotion methods e.g. Advertisement, had substantially decreased the cost of promoting the product. While standardization was influencing its customers by its wide promotion techniques, customization replaced its persuasive technique by its innovation and turned to be the most preferred one. Customization is the most effective and efficient approach towards marketing. This article brings out the conclusion that standardization along with customization would and can attract the mass market. So the marketers should take care that a combination of both is followed while getting internationalize through web.

\section{References}

[1] Kiang, M.Y. and Chi, R.T. (2001) A Framework for Analyzing the Potential Benefits of Internet Marketing. Journal of Electronic Commerce Research, 2, 158-163.

[2] Constantinescu-Dobra, A. (2011) Standardization or Adaptation in Cosmetics Websites Marketing? An Empirical Study. Technical University of Cluj Napoka. http://www.ceswp.uaic.ro/articles/CESWP2011_III2_CON.pdf

[3] Yuhmiin, C. (2009) An Exploration of the Standardization of Targeting Strategies and the Use of Promotional Disciplines on the Web: A Cross-National Study. Journal of Marketing Communications, 15, 327-343. http://dx.doi.org/10.1080/13527260802481314

[4] Dinner, I.M., Van Heerde, H.J. and Neslin, S.A. (2014) Driving Online and Offline Sales: The Cross-Channel Effects of Traditional, Online Display, and Paid Search Advertising. Journal of Marketing Research (JMR), 51, 527-545. http://dx.doi.org/10.1509/jmr.11.0466

[5] Ashraf, A.R., Thongpapanl, N. and Auh, S. (2014). The Application of the Technology Acceptance Model under Different Cultural Contexts: The Case of Online Shopping Adoption. Journal of International Marketing, 22, 68-93. http://dx.doi.org/10.1509/jim.14.0065

[6] Edelman, B. (2014) Pitfalls and Fraud in Online Advertising Metrics. Journal of Advertising Research, 54, $127-132$. http://dx.doi.org/10.2501/JAR-54-2-127-132

[7] Yuhmiin, C. (2009) An Exploration of the Standardization of Targeting Strategies and the Use of Promotional Disciplines on the Web: A Cross-National Study. Journal of Marketing Communications, 15, 327-343. http://dx.doi.org/10.1080/13527260802481314

[8] (2010) International Management Conference Paper Abstracts. Academy of Management Annual Meeting Proceedings, 1-89. http://dx.doi.org/10.5465/AMBPP.2010.54503734

[9] Edelman, B. (2014) Pitfalls and Fraud in Online Advertising Metrics. Journal of Advertising Research, 54, $127-132$. http://dx.doi.org/10.2501/JAR-54-2-127-132

[10] Knezevic, Jakovic and Strugar (2014) Potentials and Problems of Internet as a Source of Purchasing InformationExperiences and Attitudes of University Students in Croatia. http://dx.doi.org/10.3846/bme.2014.10

[11] Vanzile, J. and Hosford, C. (2013) A Trip to Bountiful. Business to Business, 98, 34-35.

[12] Constantinides, E.E. (2006) The Marketing Mix Revisited: Towards the 21st Century Marketing. Journal of Marketing Management, 22, 407-438. http://dx.doi.org/10.1362/026725706776861190

[13] Loukakou, M.D. and Membe, N.B. (2012) Product Standardization and Adaptation in International Marketing: A Case of McDonalds. Department of Economics and IT, University West. http:/hv.diva-portal.org/smash/get/diva2:543563/FULLTEXT01.pdf

[14] Meyer, E. and Bernier, I. (2010) Standardizing or Adapting the Marketing Mix across Culture: A Case Study: Agatha. Thesis in Marketing, 1-43. http://hh.diva-portal.org/smash/get/diva2:326017/FULLTEXT01.pdf

[15] Voeth, M., Herbst, U. and Liess, F. (2013) We Know Exactly What You Want: The Development of a Completely Individualised Conjoint Analysis. International Journal of Market Research, 55, 437-458. http://dx.doi.org/10.2501/IJMR-2013-038

[16] Spaulding, E. and Perry, C. (2013) Making It Personal: Rules for Success in Product Customization. http://www.bain.com/publications/articles/making-it-personal-rules-for-success-in-product-customization.aspx 
[17] Zhang, J. and Wedel, M. (2009) The Effectiveness of Customized Promotions in Online and Offline Stores. Journal of Marketing Research (JMR), 46, 190-206. http://dx.doi.org/10.1509/jmkr.46.2.190

[18] Adam, C. (2011) Influence of Adoption Factors and Risks on Ecommerce and Online Marketing. Proceedings of the International Conference Marketing_From Information to Decision, 4, 21-35.

[19] Lovelock, C. (1999) Developing Marketing Strategies for Transnationals Service Operations. Journal of Services Marketing, 13, 278-295. http://dx.doi.org/10.1108/08876049910282538

[20] Du, X.H., Jiao, J.X. and Tseng, M.M. (2006) Understanding Customer Satisfaction in Product Customization. International Journal of Advanced Manufacturing Technology, 31, 396-406. http://dx.doi.org/10.1007/s00170-005-0177-8

[21] Franke, N., Keinz, P. and Steger, C.J. (2010) Customization: A Goldmine or a Wasteland? GfK Marketing Intelligence Review, 2, 26-33.

[22] Dimitrova, B. and Rosenbloom, B. (2010) Standardization versus Adaptation in Global Markets: Is Channel Strategy Different? Journal of Marketing Channels, 17, 157-176. http://dx.doi.org/10.1080/10466691003635127

[23] International Management Conference Paper Abstracts. (2010) Academy of Management Proceedings, 2010, 1-89. http://dx.doi.org/10.5465/AMBPP.2010.54503734

[24] Mishra, S. and Misra, M. (2012) An Assessment of ROI in Online Perspective Leading to a Critical Review and Framework Development towards Standardization of ROI Practices. Journal of Internet Banking \& Commerce, 17, $1-18$.

[25] Wong, H. and Eyers, D. (2011) An Analytical Framework for Evaluating the Value of Enhanced Customisation: An Integrated Operations-Marketing Perspective. International Journal of Production Research, 49, 5779-5800. http://dx.doi.org/10.1080/00207543.2010.519738

[26] Davies, A., Brady, T. and Hobday, M. (2006) Organizing for Solutions: Systems Seller vs Systems Integrator.

[27] Duray, R. (2002) Mass Customization Origins: Mass or Custom Manufacturing? International Journal of Operations \& Production Management, 22, 314-328. http://dx.doi.org/10.1108/01443570210417614

[28] Baalbaki, I. and Malhotra, N. (1995) Standardization versus Customization in International Marketing: An Investigation Using Bridging Conjoint Analysis. Journal of the Academy of Marketing Science, 23, 182-194. http://dx.doi.org/10.1177/0092070395233003 
Scientific Research Publishing (SCIRP) is one of the largest Open Access journal publishers. It is currently publishing more than 200 open access, online, peer-reviewed journals covering a wide range of academic disciplines. SCIRP serves the worldwide academic communities and contributes to the progress and application of science with its publication.

Other selected journals from SCIRP are listed as below. Submit your manuscript to us via either submit@scirp.org or Online Submission Portal.
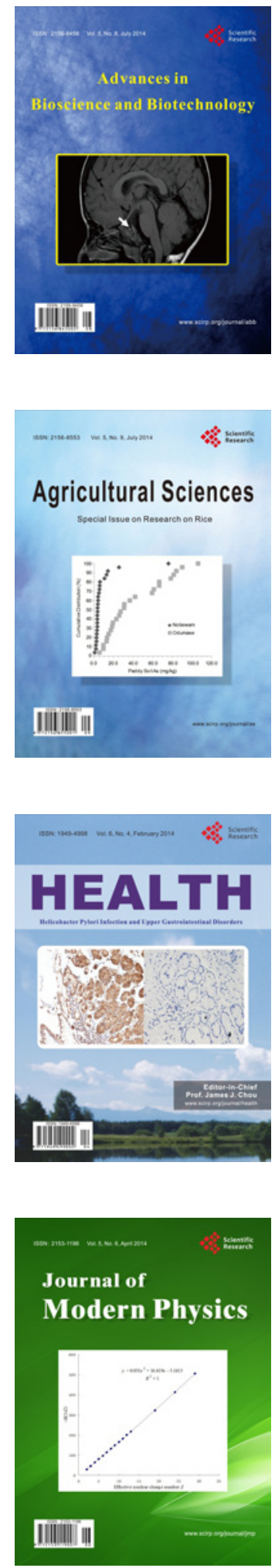
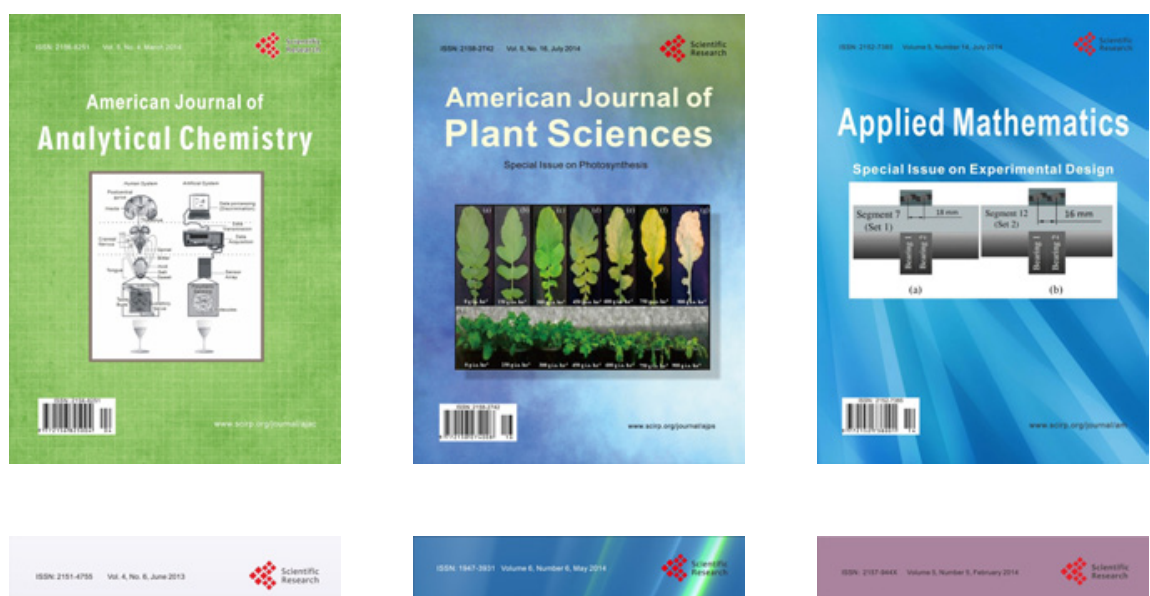

Creative Education
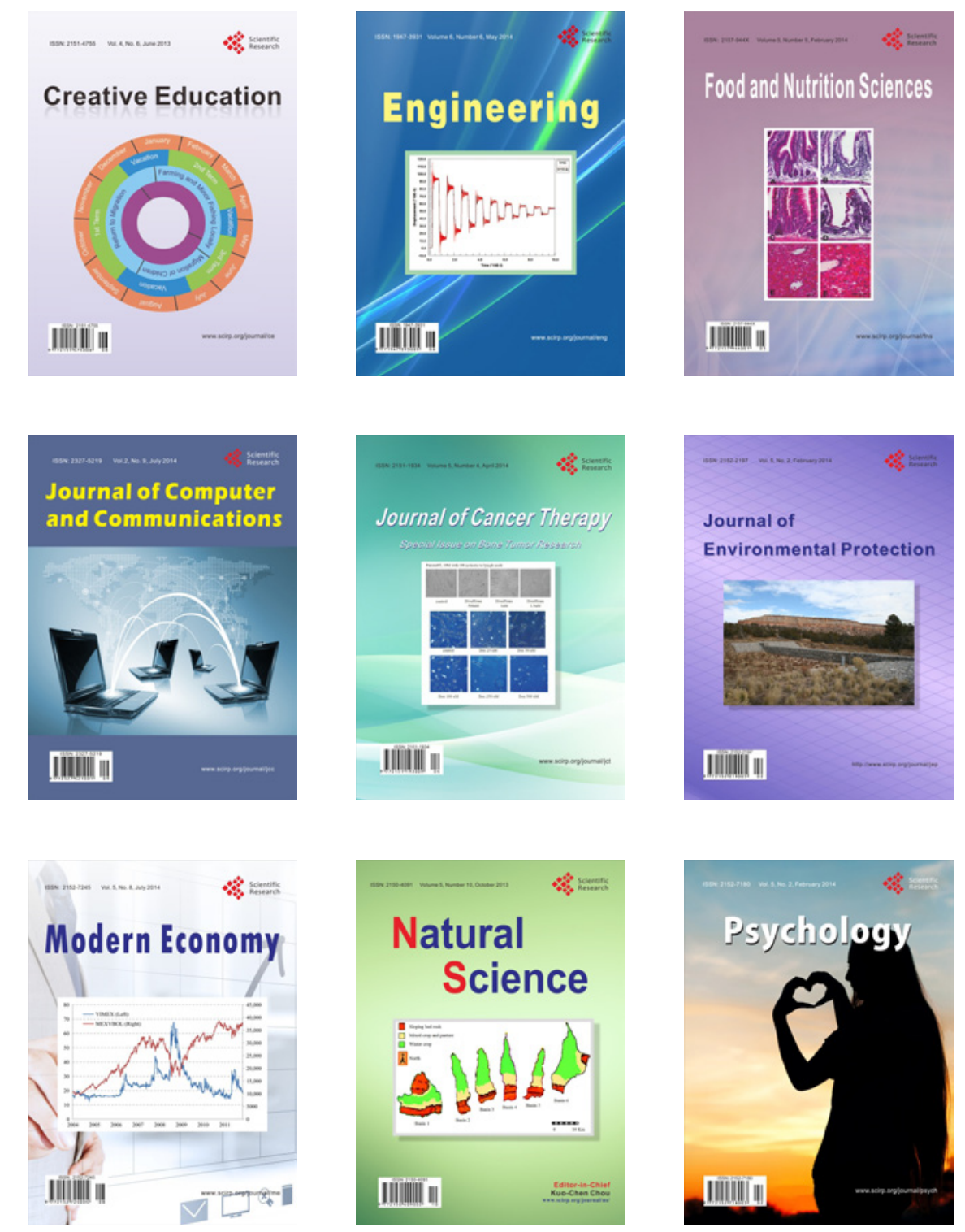